WALTER ALOISIO SANTANA

\title{
PROPOSTA DE DIRETRIZES PARA PLANEJAMENTO E GESTÃO AMBIENTAL DO TRANSPORTE HIDROVIÁRIO NO BRASIL
}

Tese apresentada à Escola Politécnica da Universidade de São Paulo para obtenção do Título de Doutor em Engenharia 
WALTER ALOISIO SANTANA

\section{PROPOSTA DE DIRETRIZES PARA PLANEJAMENTO E GESTÃO AMBIENTAL DO TRANSPORTE HIDROVIÁRIO NO BRASIL}

Tese apresentada à Escola
Politécnica da Universidade de
São Paulo para obtenção do
Título de Doutor em Engenharia

Área de concentração: Engenharia Naval e Oceânica

Orientador: Toshi-ichi Tachibana Professor Doutor do Departamento de Engenharia Naval e Oceânica da EPUSP 
Este exemplar foi revisado e alterado em relação à versão original, sob responsabilidade única do autor e com anuência de seu orientador

São Paulo, 17 de janeiro de 2008

Walter Aloisio Santana

Autor
Toshi-ichi Tachibana

Orientador

FICHA CATALOGRÁFICA

Santana, Walter Aloisio

Proposta de diretrizes para planejamento e gestão ambiental do transporte hidroviário no Brasil / W.A. Santana. -ed.rev.-São Paulo, 2008.

p.277

Tese (Doutorado) - Escola Politécnica da Universidade de São Paulo. Departamento de Engenharia Naval e Oceânica.

1.Transporte hidroviário (Aspectos ambientais) - Brasil 2.Gestão ambiental 3.Planejamento ambiental 4.Normas técnicas (Implantação) I.Universidade de São Paulo. Escola Politécnica. Departamento de Engenharia Naval e Oceânica Il.t. 


\section{DEDICATÓRIA}

Aos meus pais, pela educação, incentivo, dedicação, paciência, carinho e amor.

Ao meu filho Gustavo.

A Carolina por me proporcionar à paternidade.

Ao meu irmão Weber pelo apoio. 


\section{AGRADECIMENTOS}

A Deus, inteligência suprema, causa primeira de todas as coisas.

Ao meu orientador, Prof. Dr. Toshi-ichi Tachibana, pelo grande estímulo, paciência, dedicação, apoio, confiança, respeito, amizade e a oportunidade da orientação.

A CAPES - Coordenação de Aperfeiçoamento de Pessoal de Nível Superior pelo apoio financeiro que permitiu a execução de parte deste trabalho.

Aos meus amigos de pós-graduação pelo convívio, amizade e apoio quando preciso. Em especial ao Ari, Clemente, Diego, François, Jean, Maricruz, Newton, Rubens e Rubens (IPT). E, mais especial ainda ao Dewar, meu “irmão” desta e de outras vidas.

Aos amigos aos quais peço desculpa pelo tempo que não os dediquei, mas foi por uma causa nobre. (Anailton, Andresa, Melissa, Frajola, Batavo, Luiz Alberto, Efigênia, Ricardo, Núbia, Mineiro, Michelle, Sandro, Robson, Robinson, Heitor, Janet, Maria Carmén, Gallega, Elaine (Nani), Mariana (Mana), etc).... enfim estou pecando porque nomes faltarão aqui.

Aos professores de quem cursei disciplinas e adquiri conhecimentos ao longo desta jornada do doutoramento, Brighetti (PHD) (in memorian), Cintra (PTR), Fleury (PRO), Kokei (PHD), Sánchez (PMI) e Tachibana (PNV). Também ao professor Quintanilha (PTR) pelo apoio.

Aos funcionários do Departamento de Engenharia Naval, César, Adenilson, Damaris, Lânia e Sandra.

In memorian aos mestres Brighetti e Fadigas.

Aos meus alunos da Fatec-Carapicuíba, Fizo, Drummond e também da Poli que me ensinaram muito. "Ensinar é aprender um pouco mais a cada lição...” 
Aos meus pais Walter e Maria, pessoas simples, porém grandes em valores imensuráveis, aos quais devo toda minha formação e a própria vida, pois nesta os tesouros mais valiosos que puderam me dar foram a minha criação e formação. Essa conquista é de vocês.

Ao meu filho Gustavo por me fazer ver "eu menino” outra vez e dar sentido a minha vida.

A Carolina pelo amor, por me proporcionar à paternidade e a oportunidade de me ver menino outra vez.

Ao meu irmão Weber, pelo apoio moral, administrativo e também nos momentos difíceis como na fratura do braço.

Aos meus tios Regina \& Rogério. Aos meus primos Pedro, Mahruska, Thiago \& Greicy. Todos pelo convívio, apoio e a presença nos eventos da família (entenda churrascos e outras comelanças)

As minhas primas “Pimentas” Adriana, Bruna, Ana e Marcela pelo amor que nos une.

A Tatiana (TMD), a Bruna Esteves, Katyuska, Paula pela força que me deram em momentos específicos. A Almirlene por tudo isso e pelas informações sobre Saúde e Segurança no Trabalho.

Ao Pedro Marcon pelas informações ambientais da Marinha e a amizade. Aos grandes gurus Sandro Filippo, Antonio Camargo Júnior e Jozrael Rezende pelas valiosas contribuições e a amizade.

Aos críticos pela contribuição. Aos opositores por me fazer perseverar e fazer acreditar naquele provérbio árabe que diz “a ignorância é vizinha da maldade”.

Aos navegantes de longa data Bucanero (Cigano), Ismael e Jackson pela força astral.

A todos os meus amigos espirituais, guias, santos e orixás.

A todos que de uma maneira ou de outra, ajudou-me a conquistar mais este degrau de minha jornada. Beijos em vossas almas e coração. Muito Obrigado. Que assim seja!!!! 


\section{RESUMO}

O objetivo principal deste trabalho é propor diretrizes pró-ativas para o planejamento e gestão ambiental das hidrovias brasileiras, no que tange ao transporte comercial de cargas. $\mathrm{O}$ trabalho começa com uma abordagem panorâmica sobre o transporte hidroviário no Brasil, as vantagens deste modal, os dados sobre extensões hidroviárias, os entraves ao desenvolvimento do sistema hidroviário e o problema a ser resolvido. Para isso, foi realizada uma pesquisa exploratória buscando informações técnicas e ambientais, além de se embasar no arcabouço jurídico dos órgãos intervenientes na gestão ambiental do transporte hidroviário. O trabalho foi dividido em elementos, fases, etapas e níveis hierárquicos de gerenciamento para um sistema hidroviário. Os elementos analisados foram vias, veículos, terminais, cargas e controles. O projeto hidroviário foi dividido em etapas de planejamento, implantação, operação, manutenção e desativação/descarte. A partir destes elementos foram identificados ações, atividades, os aspectos ambientais, os impactos ambientais associados a estes, e foram propostas medidas mitigadoras para minimizar tais impactos ambientais. $\mathrm{O}$ trabalho, ainda, teve outras divisões, bem como aquela que o divide em fases de Planejamento e de Gestão Ambiental. E com relação à hierarquia de gerenciamento, o trabalho foi dividido em estratégico, tático e operacional. Na fase específica de gestão ambiental são propostas duas alternativas de implantação de Sistema de Gestão Ambiental, uma que propõe a aplicação de planos e programas ambientais para assuntos e quesitos ambientais de maior relevância, sem se preocupar em certificações ambientais, e outra, que é a aplicação da Norma ISO 14001 para os sistemas hidroviários. Com isso, como contribuição, este trabalho preocupou-se em propor planos, programas e diretrizes para o planejamento e gestão ambiental de elementos que compõem a infra-estrutura do transporte hidroviário interior no Brasil, porém termina fazendo proposições de políticas públicas, baseadas nas reais necessidades do setor.

Palavras-chave: Hidrovias. Transporte Fluvial. Transporte Hidroviário Interior. Planejamento e Gestão Ambiental. Gestão Ambiental. 


\begin{abstract}
The main objective of this work is to propose proactive directives for the environmental planning and management of Brazilian inland waterways, as for as the commercial transport of cargo is concerned. The work starts with a panoramic approach to the inland waterway transport in Brazil, the advantages of this modal, the data about inland waterway extensions, the restraints to the development of the inland waterway system and the problem to be solved. With this objective, we made an exploratory investigation searching for technical and environmental information, besides finding support in the juridical framework of the organs related to the environmental management of inland waterway transport. The work was divided into elements, phases, stages and hierarchical levels of management for a waterway system. The elements analyzed were rivers, vehicles, terminals, cargoes and control. The waterway project was divided into planning stages, implementation, operation, maintenance and deactivation/discard. From these elements, we identified actions, activities, environmental aspects and environmental impacts associated to them, proposing mitigating measures to minimize such environmental impacts. The work also had other divisions, such as the one that divides it into the Environmental Planning and Environmental Management phases. In relation to management hierarchy, the work was divided into strategic, tactic and operational. In the specific environmental management phase, we propose two alternatives for the Environmental Management System implementation, one suggesting the application of environmental plans and programs for environmental issues and queries of greater relevance, without concerns about environmental certifications, and another one, which is the application of the ISO 14001 Standard on waterway systems. Therefore, as a contribution, this work is concerned with proposing plans, programs and directives for the environmental planning and management of elements which constitute the facilities of the inland waterway transport in Brazil, but it also makes propositions of public policy, based on the real necessities of the sector
\end{abstract}

Key-Words: Waterways. Inland waterways transport. Environmental Planning and Management. Environmental management of inland waterway transport. Environmental Gestion. 


\section{RESUMEN}

El objetivo principal de este trabajo es proponer directrices pro activas para el planeamiento y gestión ambiental de las hidrovías brasileñas, que trata el transporte comercial de cargas. El trabajo empieza con un abordaje panorámico del trasporte hidroviário en Brasil, las ventajas, datos sobre las extensiones hidroviarias, las dificultades para el desenvolvimiento del sistema hidroviário y los problemas a ser resueltos. Fue realizada una investigación exploratoria buscando informaciones técnicas y ambientales, además de enfocarse en las bases jurídicas de los órganos que intervienen en la gestión ambiental del transporte hidroviário. El trabajo fue dividido en elementos, fases, etapas y niveles jerárquicos de gerenciamiento para un sistema hidroviário. Los elementos analizados fueron vías, medios de transporte, terminales, cargas y controles. El proyecto hidroviário fue dividido en etapas de planeamiento, implementación, operación, mantenimiento y desactivación/descarto. A partir de estos elementos fueron identificados acciones, actividades y aspectos ambientales, los impactos ambientales asociados $\mathrm{y}$ fueron propuestas medidas mitigadoras para minimizar tales impactos ambientales. El trabajo tiene aún otras divisiones, bien como aquella que lo divide en fases de Planeamiento y de Gestión Ambiental. Con relación a la jerarquía de gerenciamiento, el trabajo fue dividido en estratégico, táctico y operacional. En la fase especifica de gestión ambiental son propuestas dos alternativas de implementación de Sistema de Gestión Ambiental, una que propone la aplicación de planos y programas ambientales para asuntos y cuestiones ambientales, y la otra que es la aplicación de la Norma ISO 14001 para sistemas hidroviários. Con eso, como contribución, este trabajo se preocupó en proponer planos, programas y directrices para el planeamiento y gestión ambiental de elementos que componen la infraestructura del transporte hidroviário interior en Brasil, sin embargo terminando haciendo propuestas de políticas públicas, basadas en las necesidades del sector.

Palabras claves: hidrovías, transporte fluvial, transporte hidroviário interior, planeamiento y gestión ambiental de hidrovías, gestión ambiental, gereciamiento ambiental 


\section{RÉSUMÉ}

L'objectif principal de ce travail est proposer des directives pró-actifs pour la planification et gestion environnementale des voies fluviales navigables brésiliennes, dans lesquelles concerne au transport commercial de chargements. Le travail commence avec un abordage panoramique sur le transport par voie fluviale au Brésil, en avantages de ce modal, les données sur des extensions des voies fluviales navigables, les entraves au développement du système par voie navigable et le problème à être décidé. Pour cela, etait réalisée une recherche exploratrice en cherchant informations techniques et environnementaux, outre se basera dans la carcasse juridique des agences intervenantes dans la gestion environnementale du transport par voie navigable. Le travail a été divisé à des éléments, phases, étapes et niveaux hiérarchiques de gestion pour un système des voies fluviales navigables. Les éléments analysés ont été des manières, véhicules, terminaux, chargements et contrôles. Le projet des voies fluviales navigables a été divisé dans des étapes de planification, d'implantation, d'opération, de manutention et désactivation/rejet À partir de ces éléments ont été identifiés des actions, activités, les aspects environnementaux, les impacts environnementaux associés à ceux-ci, et ont été proposés des mesures mitigatives pour minimiser tels impacts environnementaux. Le travail, encore, a eu autres divisions, ainsi que celle qui le divise dans des phases de Planification et de Gestion Environnementale. Et concernant la hiérarchie de gestion, le travail a été divisé dans stratégique, tactique et opérationnel. Dans la phase spécifique de gestion environnementale sont proposées deux alternatives d'implantation de Système de Gestion Environnementale, un laquelle propose l'application de plans et de programmes environnementaux pour sujets et de questions environnementales de plus grande importance, sans s'inquiétera dans des homologations environnementales, et autre, qui est l'application de la Norme ISO 14001 pour les systèmes des voies fluviales navigables. Avec cela, comme contribution, ce travail s'est inquiété à proposer des plans, programmes et directives pour la planification et gestion environnementale d'éléments qui composent l'infrastructure du transport par voie navigable intérieur au Brésil, néanmoins finit en faisant des propositions de politiques publiques, basée sur les réelles nécessités du secteur.

Mots clé: voies fluviales navigables ; transport fluvial ; transport par voie fluviale navigable intérieure ; planification et gestion environnementale de voies fluviales navigables ; gestion environnementale. 


\section{LISTA DE FIGURAS}

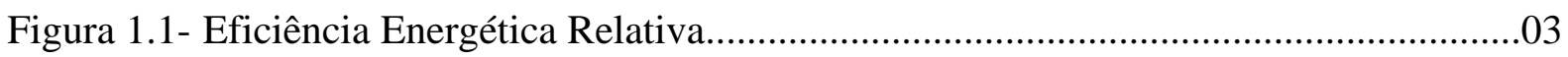

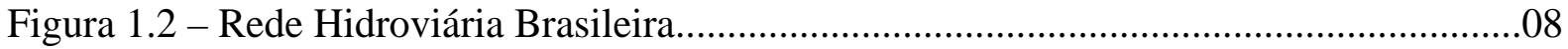

Figura 1.3 - Embarcação fluvial de transporte de GLP no rio Madeira...................................10

Figura 5.1 - Distribuição Geográfica da Jurisdição das Administradoras Hidroviárias..........43

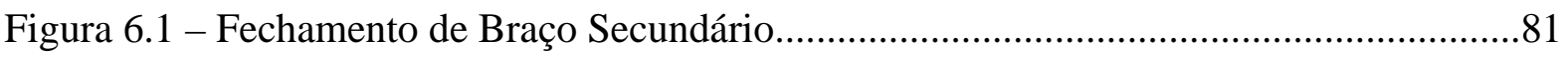

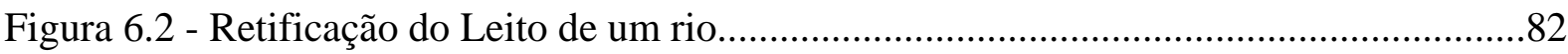

Figura 6.3 - Contração Lateral do Leito de um Rio................................................................82

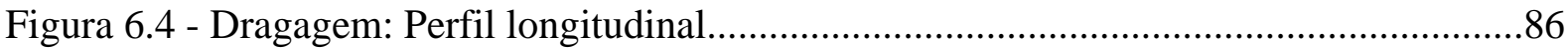

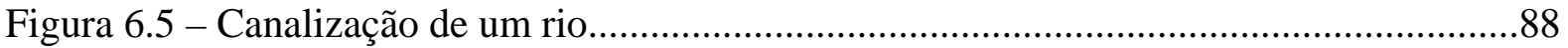

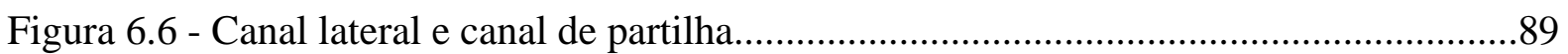

Figura 7.1 - Corrente de riscos de acidentes em elementos hidroviários..............................176

Figura 7.2 - Estrutura Básica de uma Barreira de Contenção...............................................193

Figura 7.3 - Configurações de Barreiras de Contenção...................................................194

Figura 7.4 - Barreira de contenção de óleo..........................................................................195

Figura 7.5 - Skimmer de Disco e Skimmer de fita................................................................195

Figura 7.6 - Barcaça Recolhedora de Óleo............................................................................196

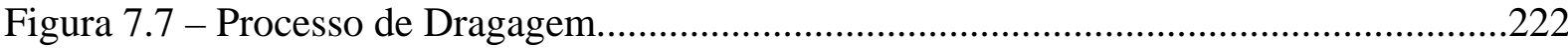

Figura 7.8 - Curva obstruída pela vegetação flutuante (balseiro............................................225

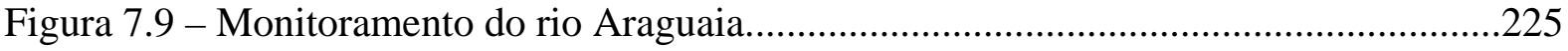

Figura7.10 - Monitoramento do Rio Araguaia..............................................................226

Figura 7.11 - Convenção de bóias metálicas na Hidrovia Tocantins -Araguaia....................227

Figura 7.12 - Trabalho de recolhimento, concerto e de manutenção das bóias......................227

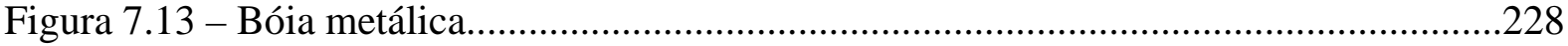

Figura 7.14 - Bóia de material composto de polietileno e poliuretano..................................228

Figuras 7. 15 - Implantação de farolete de margem na hidrovia do rio Paraguai....................229

Figura 7.16- Implantação de placa de margem na hidrovia do rio Paraguai..........................229

Figura 7.17 - Espiral da melhoria contínua da qualidade ambiental.....................................234 


\section{LISTA DAS TABELAS}

Tabela 1.1 - Custos Sociais em relação das modalidades de Transporte......................... 04

Tabela 2.1 - Comparação e Análise dos assuntos abordados pelos autores pesquisados 22

Tabela 4.1 - Classificação das hidrovias européias segundo a CEMT...................... 30

Tabela 4.2 - Classificação das hidrovias segundo a PIANC........................................... 31

Tabela 4.3 - Gabaritos das Hidrovias Brasileiras.......................................... 32

Tabela 4.4 - Transporte Hidroviário Interior no Mundo - Extensões Navegáveis......... 35

Tabela 4.5 - Bacias Hidrográficas Brasileiras e as Extensões Hidroviárias.................... 36

Tabela 4.6 - Rede Hidroviária Brasileira - Detalhada...................................................... 36

Tabela 5.1 Administrações Hidroviárias e as Companhias Docas................................ 42

Tabela 6.1 - Classificação dos Impactos Relativos aos Sistemas de Transportes........... 61

Tabela 6.2 - Proposta Sintética para o desenvolvimento da tese......................................63 63

Tabela 6.3 - Visão Sistêmica (sintética) dos elementos, fases do projeto e os efeitos 69 ambientais

Tabela 6.4-A - Análise dos Impactos - Instalação e uso do Canteiro de Obras Contratação de força trabalho/ Alocação de mão-de-obra

Tabela 6.4-B - Análise dos Impactos - Instalação e uso do Canteiro de Obras- Execução 74 de Obras Civis e Terraplenagem

Tabela 6.4-C - Análise dos Impactos - Instalação e uso do Canteiro de Obras - Geração de 75 efluentes líquidos/ Emissão de gases e poeiras de usinas.

Tabela 6.4-D - Análise dos Impactos - Instalação e uso do Canteiro de Obras - Geração de 76 Resíduos Sólidos.

Tabela 6.4-E - Análise dos Impactos - Instalação e uso do Canteiro de Obras - Geração de 77 Resíduos Sólidos.

Tabela 6.5 - Tipos de vias Navegáveis e as técnicas para melhorar a navegabilidade.... 79

Tabela 6.6 - Principais tipos de dragas......................................................................... 85

Tabela 6.7-A - Análise dos Impactos - Obras e Serviços para melhorar a navegabilidade 91

- Obras de Dragagem.

Tabela 6.7-B - Análise dos Impactos - Obras e Serviços para melhorar a navegabilidade 92

- Obras de Dragagem

Tabela 6.7-C - Análise dos Impactos - Obras e Serviços para melhorar a navegabilidade 93 - Obras de Dragagem.

Tabela 6.7-D - Análise dos Impactos - Obras e Serviços para melhorar a navegabilidade 94 - Obras de derrocamentos.

Tabela 6.7-E - Análise dos Impactos - Obras e Serviços para melhorar a navegabilidade 95 - Construção de Canais Artificiais

Tabela 6.7-F - Análise dos Impactos - Obras e Serviços para melhorar a navegabilidade 96 
- Obras de retificação de cursos d'água e demais trabalhos de regularização.

Tabela 6.7-G - Análise dos Impactos - Obras e Serviços para melhorar a navegabilidade 97

- Obras de Canalização (Transposição).

Tabela 6.7-H - Análise dos Impactos - Obras e Serviços para melhorar a navegabilidade 98

- Obras de Canalização (Transposição)......

Tabela 6.7-I - Análise dos Impactos - Obras e Serviços para melhorar a navegabilidade 99 - Serviços de Sinalização e Balizamento.

Tabela 6.8-A - Análise dos Impactos - Obras e Serviços para Construção de Terminais - 101 Desapropriação de áreas.

Tabela 6.8-B - Análise dos Impactos - Obras e Serviços para Construção de Terminais Desmatamento e limpeza do terreno.

Tabela 6.8-C - Análise dos Impactos - Obras e Serviços para Construção de Terminais Execução de obras de terraplenagem.

Tabela 6.8-D - Análise dos Impactos - Obras e Serviços para Construção de Terminais Execução de obras de acostagem e de proteção/ Obras de drenagem e derrocamento.

Tabela 6.8-E - Análise dos Impactos - Obras e Serviços para Construção de Terminais Execução de obras civis na área do retroporto.

Tabela 6.9 - Análise dos Impactos - Existência de Infra-estrutura Hidroviária -

Tabela 6.10A - Análise dos Impactos - Operação dos Terminais - Manipulação e 118 Armazenamento de Cargas (Granel Sólido)...

Tabela 6.10B - Análise dos Impactos - Operação dos Terminais - Manipulação e 119 Armazenamento de Cargas (Granel Líquido).

Tabela 6.10C - Análise dos Impactos - Operação dos Terminais - Manipulação e 120 Armazenamento de Cargas (Carga Geral).

Tabela 6.10D - Análise dos Impactos - Operação dos Terminais - Atividades Industriais no 121 entorno do terminal.

Tabela 6.10E - Análise dos Impactos - Operação dos Terminais - Expansão e 122 Desenvolvimento do Terminal// Interface Terminal /Núcleos urbanos.

Tabela 6.11 - Classes de produtos perigosos................................................................ 126

Tabela 6.12 Normas Internacionais para os tipos de cargas perigosas........................... 127

Tabela 6.13A - Análise dos Impactos - Operação das Embarcações - Limpeza e Lavagem de 133 Tanques, Conveses, Porões e Praça de Máquinas.

Tabela 6.13B - Análise dos Impactos - Operação das Embarcações - Operações de Lastro e 134 deslastro/ Navegação e trânsito na via.

Tabela 6.13C - Análise dos Impactos - Operação das Embarcações - Transporte de Produtos 135 Perigosos.

Tabela 6.13D - Análise dos Impactos - Operação das Embarcações - Geração de demais resíduos.

Tabela 6.14 Largura mínima da faixa de mata ciliar e as situações de aplicação 
Tabela 6.16 Processos de Gerenciamento de Riscos PMBOK, CMMI-SW e RUP 150

Tabela 6.17 Tipologia de ordem de grandeza para derramamentos de óleo 162

Tabela 6.18 Etapas para elaboração das Cartas de Sensibilidade 163

Tabela 7.1 Aplicações das Cartas SAO nos Planos Ambientais 166

Tabela 7.2 Estágios da corrente de risco de acidentes em hidrovias 177

Tabela 7.3 Relação entre cartas SAO, planos de contingências e volumes derramados 181

Tabela 7.4 Características estruturais das barreiras de contenção 194

Tabela 7.5 Classificação dos Óleos quanto à Gravidade Específica 200

Tabela 7.6 Caracterização de fontes poluidoras em bacias hidrográficas 210

Tabela 7.7 Principais características dos reservatórios e a qualidades da água 211

Tabela 7.8 Proposta de implementação e operação da Norma ISO 14001 para 235

Tabela 7.9 Proposta de implementação e operação da Norma ISO 14001 para 237 sistemas hidroviários operantes

Tabela 7.10 Atores e Responsabilidades da Implementação do SGA numa empresa 246

Tabela 8.1 Matriz de transporte de cargas nacional (atual e previsão). Em percentual 263 


\section{LISTA DAS ABREVIATURAS}

ABNT - Associação Brasileira de Normas Técnicas

AHIPAR - Administração da Hidrovia do Paraguai

AHITAR - Administração da Hidrovia do Tocantins-Araguaia

AHMOC - Administração da Hidrovia da Amazônia Ocidental

AHMOR - Administração da Hidrovia da Amazônia Oriental

AHNOR - Administração da Hidrovia do Nordeste

AHRANA - Administração da Hidrovia do Paraná

AHSFRA - Administração da Hidrovia do São Francisco

AHSUL - Administração da Hidrovia do Sul

AHRANA - Administração da Hidrovia do Paraná

AIA - Avaliação de Impacto Ambiental

ANA - Agência Nacional de Águas

ANP - Agência Nacional do Petróleo, Gás Natural e Biocombustíveis.

ANTAQ - Agência Nacional de Transportes Aquaviários.

ANVISA - Agência Nacional de Vigilância Sanitária

CEEIBH - Comitês Especiais de Estudos Integrados de Bacias Hidrográficas

CEMT - Comissão Européia dos Ministros de Transporte (Commission Europenne des

Ministres des Transport)

CESP - Companhia Energética de São Paulo

CETESB - Companhia de Tecnologia de Saneamento Ambiental

CF - Constituição Federal

CIPA - Comissão Interna de Prevenção de Acidentes

CNRH - Conselho Nacional dos Recursos Hídricos

CODESP - Companhia de Docas do Estado de São Paulo

CONAMA - Conselho Nacional do Meio Ambiente

CONIT - Conselho Nacional de Integração de Políticas de Transportes

DAEE - Departamento de Água e Energia Elétrica

DHI - Departamento de Hidrovias Interiores

DMM - Departamento de Marinha Mercante

DNIT - Departamento Nacional de Infra-estrutura em Transportes

DNPVN - Departamento Nacional de Portos e Vias Navegáveis

DP - Departamento de Portos

DPC - Diretoria de Portos e Costa (Marinha Brasileira)

EIA - Estudo dos Impactos Ambientais

EMBRAPA - Empresa Brasileira de Pesquisas Agropecuárias

EPI - Equipamentos de Proteção Individual

FAPESP - Fundo de Amparo à Pesquisa do Estado de São Paulo

FATEC - Faculdade de Tecnologia

FUNAI -Fundação Nacional do Índio

GEIPOT - Empresa Brasileira de Planejamento de Transportes

GLP - Gás liquefeito de petróleo

GTI - Grupo de Trabalho Interministerial

IBAMA - Instituto Brasileiro do Meio Ambiente e dos Recursos Naturais Renováveis

IBP - Instituto Brasileiro de Petróleo

IPHAN - Instituto do Patrimônio Histórico e Artístico Nacional

IPT - Instituto de Pesquisas Tecnológicas do Estado de São Paulo.

INMET - Instituto Nacional de Meteorologia

INMETRO - Instituto Nacional de Metrologia, Normalização e Qualidade Industrial. 
INPA - Instituto Nacional de Pesquisas da Amazônia

ISO - Organização Internacional de Padronização (International Organization for Standardization)

LESTA - Lei de Segurança do Tráfego Aqüaviário

L.I - Licença de Instalação

L.O - Licença de Operação

L.P - Licença Prévia

MARPOL -Convenção Internacional para Prevenção da Poluição por Navios (Prevention of Poluttion from Ships)

MD - Ministério da Defesa

MERCOSUL - Mercado Comum do Cone Sul

MIN - Ministério da Integração Nacional

MP- Ministério Público

MMA - Ministério do Meio Ambiente

MME - Ministério de Minas e Energia

MPE - Ministério Público Estadual

MPF - Ministério Público Federal

MT - Ministério dos Transportes

N.A - Nível d'água

NBR - Norma Brasileira Reguladora

NORMAN - Normas de Autoridade Marítima

NORTAM - Norma Técnica Ambiental

NORTEC - Norma Técnica de Procedimentos

NR - Norma Reguladora

O/D - Matriz Origem-Destino

OEMA - Órgãos Estaduais de Meio ambiente

ONG - Organizações não Governamentais

ONU - Organizações das Nações Unidas

PA - Plano de Área

PAM - Plano de Auxílio Mútuo

PCA - Plano de Controle Ambiental

PCE - Planos de Contingências e Emergências

PETROBRÁS - Petróleo Brasileiro S.A

PEI - Plano de Emergência Individual

PENPO - Plano de Emergência de Navio para Poluição por Óleo

PGAL - Proposta de Plano de Gerenciamento de Água de Lastro

PGR - Programa de Gerenciamento de Risco

PIATAM - Potenciais Impactos Ambientais no Transporte Fluvial de Gás Natural e Petróleo na Amazônia

P.I.A.N.C - Permanent International Association Navigation Congresses

PIB - Produto Interno Bruto

PLA - Processo de Licenciamento Ambiental

PNC - Plano Nacional de Contingência

PNMA - Política Nacional do Meio Ambiente

PNV - Plano Nacional de Viação

PPP - Parcerias Públicas Privadas

PPRA - Programa de Prevenção de Riscos Ambientais

PROAMAR - Programa de Auxílio Mútuo dos Terminais Marítimos no Espírito Santo

PORTOBRÁS - Empresa Brasileira de Portos S. A.

RIMA - relatório de impactos ao meio ambiente 
SGA - Sistema de Gestão Ambiental

SIGest/H - Sistema Integrado de Gestão do Desenvolvimento da Hidrovia

SISNAMA - Sistema Nacional de Meio Ambiente

SISNOLEO - Sistema de Informações sobre Incidentes de Poluição por Óleo

SNGRH - Sistema Nacional de Gerenciamento Recursos Hídricos

SRH - Secretaria de Recursos Hídricos

STA - Secretaria de Transportes Aqüaviários

SOBENA - Sociedade Brasileira de Engenharia Naval

TVA - Tennessee Valey Authority

UFAM - Universidade Federal do Amazonas

UFRJ - Universidade Federal do Rio de Janeiro

UFSC - Universidade Federal de Santa Catarina

UNESP - Universidade Estadual Paulista

USP - Universidade de São Paulo 


\section{SUMÁRIO}

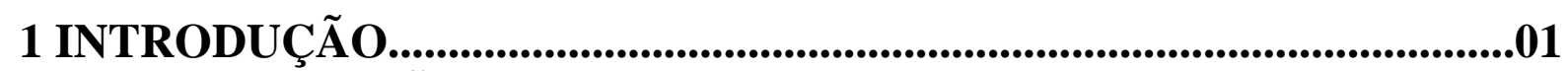

1.1 CONSIDERAÇÕES INICIAIS..................................................................

1.2 APRESENTAÇÃO DO PROBLEMA.......................................................11

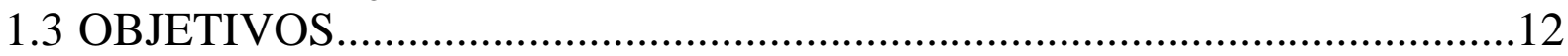

1.4DELINEAMENTO DO TRABALHO..........................................................

2 REVISÃO DE LITERATURA....................................................................15

3 ASPECTOS METODOLÓGICOS................................................................23

4 O SISTEMA DE TRANSPORTE HIDROVIÁRIO INTERIOR................25

4.1 CONSIDERAÇÕES INICIAIS..................................................................25

4.2 CONCEITO DE NAVEGABILIDADE......................................................27

4.3 CLASSIFICAÇÃO DAS VIAS NAVEGÁVEIS..............................................29

4.3.1 Quanto à artificialidade da via.......................................................................................29

4.3.2 Quanto às dimensões e a capacidade de carga das embarcações..................................29

4.4 REDE HIDROVIÁRIA BRASILEIRA.......................................................35

5 TRANSPORTE HIDROVIÁRIO INTERIOR E A LEGISLAÇÃO

BRASILEIRA...................................................................................................38

5.1 CONSIDERAÇÕES GERAIS ……………………………………….......38

5.2 LICENCIAMENTO AMBIENTAL..........................................................50

5.3 LICENÇAS AMBIENTAIS........................................................................52

6 PROPOSTA DE PLANEJAMENTO AMBIENTAL.....................................55

6.1 CONSIDERAÇÕES INICIAIS.................................................................55

6.2 CONCEITUAÇÃO DE IMPACTOS AMBIENTAIS.....................................56

6.3 ETAPAS DE IMPLANTAÇÃO DE UM SISTEMA DE TRANSPORTE E

OS IMPACTOS AMBIENTAIS.......................................................................58

6.4 AVALIAÇÃO DE IMPACTO AMBIENTAL …………………………......59

6.5 CARACTERIZAÇÃO DE IMPACTOS AMBIENTAIS...............................60

6.6 PROPOSTA DE PLANEJAMENTO AMBIENTAL.....................................62

6.7 ETAPAS PARA O PLANEJAMENTO AMBIENTAL...................................65

6.7.1 Etapa 1 - Planejamento do Projeto Hidroviário.............................................................65

6.7.2 Etapa 2 - Implantação do Projeto Hidroviário....................................................................70

6.7.2.1 Instalação e Uso do Canteiro de Obras........................................................................71

6.7.2.2 Melhoramentos das Vias Navegáveis - Obras e Serviços...............................................77

6.7.2.2.1 Regularização do Leito dos Rios............................................................................80

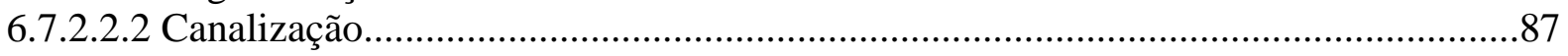

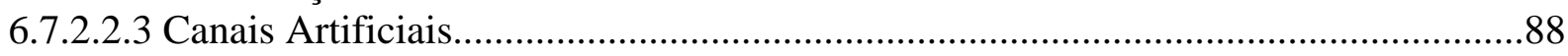

6.7.2.2.4 Serviços de Sinalização e Balizamento..........................................................................89

6.7.2.2.5 Análise dos Impactos Ambientais das Atividades de Melhoramento da Via.............90

6.7.2.3 Construção de Terminais Hidroviários Interiores...........................................................99

6.7.3 Etapa 3 - Operação do Projeto Hidroviário..................................................................106

6.7.3.1 Principais Impactos Ambientais da Existência da Infra-Estrutura para o Transporte

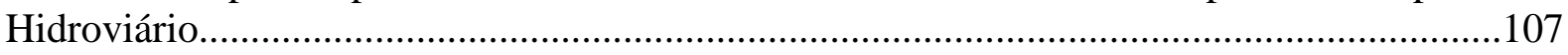

6.7.3.2 Análise dos Impactos Ambientais da Existência de Infra-Estrutura de THI...............108

6.7.3.3 Operação de terminais hidroviários............................................................................110 


\subsection{Atividades Geradoras de Impacto Ambiental na Operação dos Terminais e}

Portos.

6.7.3.3.2 Análise dos Impactos Ambientais da Operação de Terminais

6.7.3.4 Operação de Embarcações Hidroviários...................................................................123

6.7.3.4.1 Atividades e Ações que causam impactos...........................................................123

6.7.3.4.2 Resíduos Gerados pelas Embarcações..........................................................130

6.7.3.4.3 Análise dos Impactos Ambientais da Operação das Embarcações.....................132

6.7.4 Etapa 4 - Manutenção do Projeto Hidroviário..........................................................137

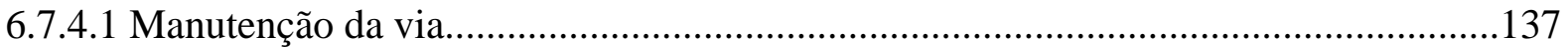

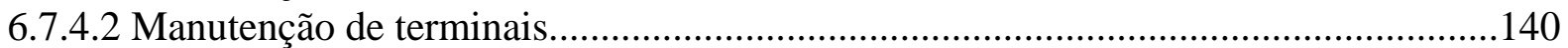

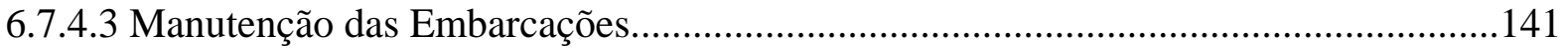

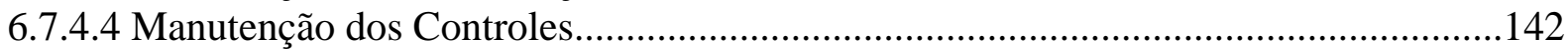

6.7.5 Etapa 5 - Desativação/Descarte do Projeto Hidroviário.............................................142

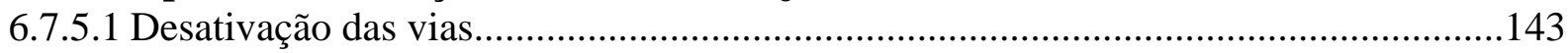

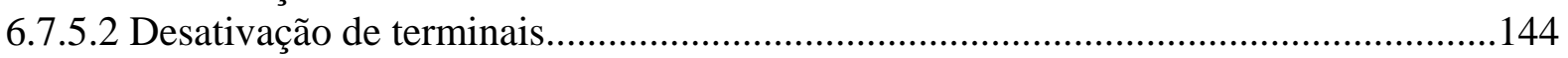

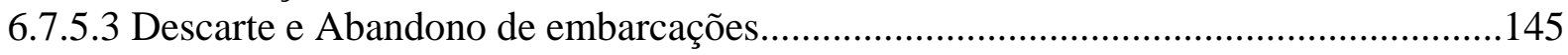

6.7.5.4 Desativação e descarte de equipamentos de controle.................................................146

6.8 PLANEJAMENTO DE GERENCIAMENTO DE RISCO...........................147

6.8.1. Estudo do Risco..................................................................................................147

6.8.2 Riscos de Acidente Ambiental de Natureza Tecnológica em Hidrovias...................153

6.8.3 Análise de Risco de Acidentes Tecnológicos............................................................154

6.9 CARTAS DE SENSIBILIDADE AMBIENTAL PARA

DERRAMAMENTOS DE ÓLEO..............................................................................................157

7 PROPOSTA DE GESTÃO AMBIENTAL................................................164

7.1 PROPOSTA DE PROGRAMAS E PLANOS AMBIENTAIS.....................164

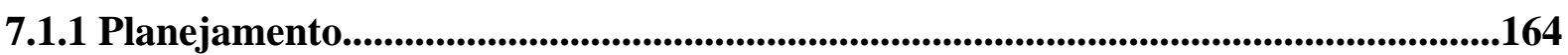

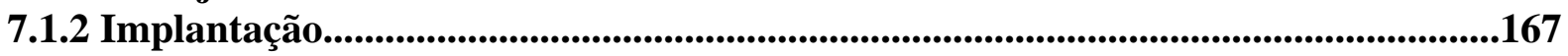

7.1.2.1 Programa de Educação Ambiental da Comunidade e Operários ................................167

7.1.2.2 Plano de Desapropriação e realocação da população afetada.....................................168

7.1.2.3 Plano de Recuperação de Áreas Degradadas (PRAD)..............................................169

7.1.2.4 Plano de Salvamento Arqueológico.........................................................................169

7.1.2.5 Plano de Manejo e Monitoramento da Fauna Terrestre............................................170

7.1.2.6 Planos de Criação de Estações Ecológicas................................................................170

7.1.2.7 Plano de Monitoramento da Qualidade das Águas.................................................171

7.1.2.8 Plano de Monitoramento de Ictiofauna, Comunidades Aquáticas e Recursos

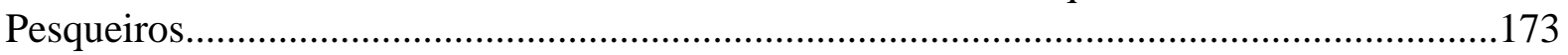

7.1.2.9 Plano de Controle de Qualidade do Ar na Implantação de Obras Hidroviárias..........173

7.1.2.10 Plano de Controle de Ruído e Vibrações...................................................................174

7.1.3 Operaçãa..........................................................................................................................................174

7.1.3.1 Programa de Gerenciamento de Risco (PGR).......................................................175

7.1.3.2 - Planos de Contingências e Emergências..............................................................179

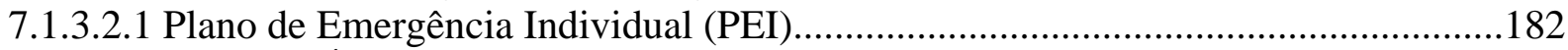

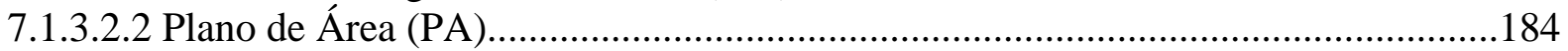

7.1.3.2.3 Plano Nacional de Contingência.............................................................................188

7.1.3.2.4 Plano de Ações para Contingências e Emergências.................................................191 
7.1.3.3 - Plano de Emergência de Navio para Poluição por Óleo (PENPO). .198

7.1.3.4 Plano de Gerenciamento de Água de Lastro (PGAL) .................................................202

7.1.3.5 - Programa de Monitoramento e Controle da Qualidade da Água..............................208

7.1.3.6 Programa de Monitoramento e Controle de Resíduos Oleosos, Líquidos e

Efluentes.

7.1.3.7 Programa de Gerenciamento de Resíduos Sólidos.

7.1.3.8 Programa de Monitoramento e Controle da Qualidade do Ar...................................214

7.1.3.9 Plano de Controle de Ruído e Vibrações...................................................................215

7.1.3.10 Plano de Lazer e Turismo Ecológico....................................................................216

7.1.3.11 Programa de Segurança e Saúde do Trabalho Portuário...........................................216

7.1.3.12 Programa de Estudo de Viabilidade Individual para a Navegação..........................217

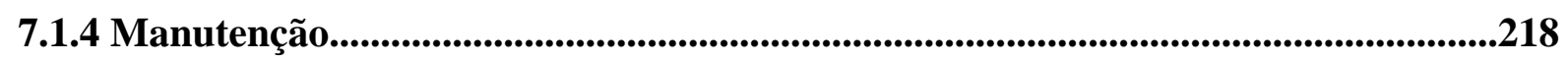

7.1.4.1 Programa de Manutenção da Navegabilidade..........................................................218

7.1.4.1.1 Programa de Manutenção e Recuperação das Matas Ciliares...................................218

7.1.4.1.2 Plano de Dragagens Manutentivas......................................................................219

7.1.4.1.3 - Plano de Dragagens Ambientais......................................................................223

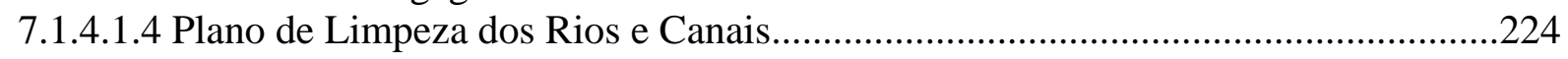

7.1.4.2 Plano de Monitoramento do regime hidrológico.....................................................225

7.1.4.3 Plano de Manutenção dos Sistemas de Controle.......................................................226

7.1.5 Desativação /Descarte..................................................................................................................229

7.1.5.1 Programas de Desativação dos prédios, estruturas, tanques, silos, equipamentos e veículos sem danos ao meio ambiente............................................................................230

7.1.5.2 Programas para tombamento histórico de patrimônios que significaram progressos locais e regionais......

7.1.5.3 Programas de incentivo à pesquisa (para escolas técnicas, tecnológicas e engenharias)

sobre embarcações descartadas, afundadas, encalhadas e obsoletas........................................231

7.1.5.4 Programas especiais de cuidados do abandono das embarcações para o meio

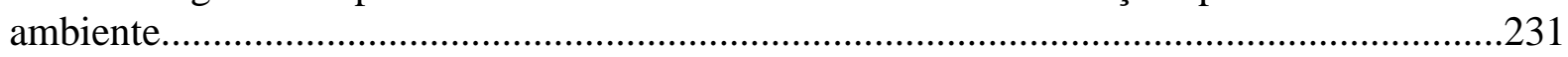

7.1.6 Considerações para Projetos Hidroviários já existentes.............................................232

7.2 IMPLEMENTAÇÃO E OPERAÇÃO DO SISTEMA DE GESTÃO AMBIENTAL DE ACORDO COM A NORMA ABNT NBR ISO

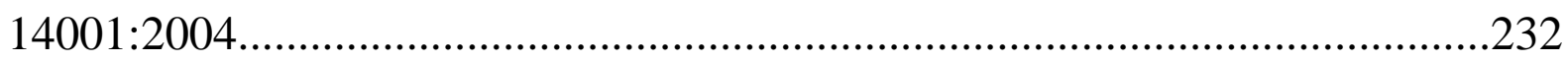

7.2.1 Etapa 1 - Política Ambiental......................................................................................237

7.2.2 Etapa 2 - Planejamento.......................................................................................239

7.2.3 Etapa 3 - Implementação e Operação...........................................................................244

7.2.4 Etapa 4 - Avaliação Periódica e Revisão.....................................................................249

7.2.5 Etapa 5 - Análise Crítica e Melhoria Contínua...........................................................251

7.3 PROPOSTA DE POLÍTICAS-ADMINISTRATIVAS DE

PLANEJAMENTO E GESTÃO AMBIENTAL PARA CONTRIBUIÇÃO COM

O PLANO NACIONAL DE HIDROVIAS...................................................252

8 CONSIDERAÇÕES FINAIS.....................................................................259

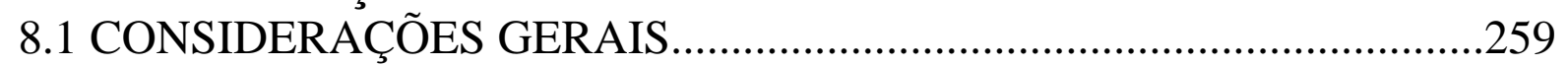

8.2 PROPOSTAS DE TRABALHOS FUTUROS E RECOMENDAÇÕES....263

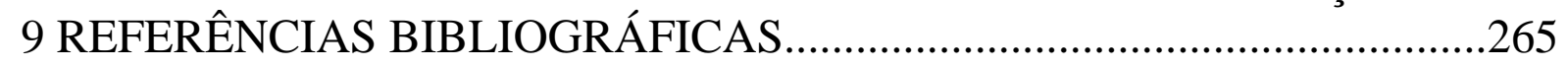

